\title{
TRADICIONALNO I SAVREMENO U PRIRUČNICIMA ZA SRPSKI KAO STRANI JEZIK
}

Katarzyna Liber i Slavica Prpa, Priručnik za srpski kao strani jezik, Kraków: Wydawnictwo Uniwersytetu Jagiellońskiego, 2011, str. 272; Katarzyna Liber i Slavica Prpa, Kultura živog jezika, Kraków: Wydawnictwo Uniwersytetu Jagiellońskiego, 2012, str. 140.

1. Poslednjih godina pokazuje se sve veće interesovanje za učenje srpskog jezika kao stranog. Pored toga, postoje strani univerziteti na kojima se srbistika izučava kao poseban smer. Jedan od univerziteta koji neguje tradiciju izučavanja srbistike jeste i Jagelonski univerzitet u Krakovu. Početkom ove decenije, kao rezultat rada sa studentima srpske filologije na Institutu za slovensku filologiju spomenutog univerziteta, nastao je komplet priručnika za srpski kao strani jezik.

Komplet čine dva priručnika: Priručnik za srpski kao strani jezik ${ }^{l}$, izdat 2011. godine i Kultura živog jezika ${ }^{2}$, objavljen godinu dana kasnije. Autorke su Katarzyna Liber i Slavica Prpa, u to vreme zaposlene na Institutu za slovensku filologiju na Jagelonskom univerzitetu u Krakovu. Kako same autorke navode u predgovoru, ideja za nastanak PZSKSJ nastala je: „(...) iz, na našim časovima potvrđene, potrebe za objektivnim vežbama prilagođenim cilju unapređenja komunikacije, kao i iz našeg uverenja da za učenje srpskog jezika ne postoji dovoljno priručnika“" (Liber-Prpa 2011: 11). Dalje navode kako je zamisao bila da se napravi priručnik koji odgovara svakodnevnim potrebama na časovima na različitim nivoima, odnosno priručnik koji će se koristiti i za učenje i za usavršavanje znanja srpskog jezika. Naglašavaju da su vodile računa o smernicama Zajedničkog evropskog referentnog okvira ${ }^{3}$. Napominju i da su gramatičke vežbe, koje se nalaze u posebnom odeljku, napravljene bez pretenzije da se usklade sa određenim temama, kao i to da je priručnik usmeren na komunikativne zadatke.

Prema Šeldonu (Sheldon 1988: 237), evaluacija udžbenika se sprovodi iz dva osnovna razloga - da olakša izbor udžbenika ili upozna nastavnike sa

\footnotetext{
${ }^{1} \mathrm{U}$ daljem tekstu: PZSKSJ.

${ }^{2} \mathrm{U}$ daljem tekstu: $K Z \check{J} J$.

${ }^{3} \mathrm{U}$ daljem tekstu: $Z E O$.
} 
eventualnim prednostima i nedostacima materijala. Razlog za evaluaciju posmatranog kompleta priručnika mogao bi se odrediti kao sinteza oba navedena. Kaningsvort (Cunningsworth 1995:14) upućuje na tri različite vrste evaluacije nastavnog materijala: 1) vrednovanje koje prethodi upotrebi; 2) procena tokom upotrebe i 3) evaluacija nakon upotrebe, koja predstavlja retroaktivno procenjivanje potencijala udžbenika i može biti korisna za realno sagledavanje prednosti i mana. Evaluacija koja sledi pripada trećem tipu i, u skladu sa svim prethodno navedenim, u nastavku će se predstaviti i analizirati priručnici u pogledu obima, nivoa učenja jezika kojima su namenjeni, tema, gramatičkih i leksičkih sadržaja i mogućnosti za razvijanje različitih jezičkih veština, uz poseban osvrt na zahteve ZEO koji su i same autorke navele kao smernicu za konstruisanje navedenih priručnika.

2. PZSKSJ već na osnovu dizajna naslovne strane (Slika 1) ukazuje na određene teme koje će u njemu biti zastupljene. Naime, fotografije asociraju na: prirodu, hranu, sport i rekreaciju, posao i komunikaciju, putovanja. Što se sadržaja tiče, podeljen po nivoima kojih ima ukupno šest, od A1 do C2. Na prvom nivou (str. 1738) zastupljene su sledeće teme: Upoznavanje, Porodica, Osobine čoveka, Profesije i zanimanja, Vreme $i$ vremenska prognoza, $U$ kući, Grad $i$ putovanje i $U$ kupovini. Tematske oblasti u okviru drugog nivoa (str. 41-58) su: Škola, Kod lekara, Sport i slobodno vreme, Na poslu, Priroda, Praznici, Komunikacija i Film i pozorište. Treći nivo (str. 61-94) sadrži sledeće teme: Obrazovanje, Posao, Moda, Turizam, Red

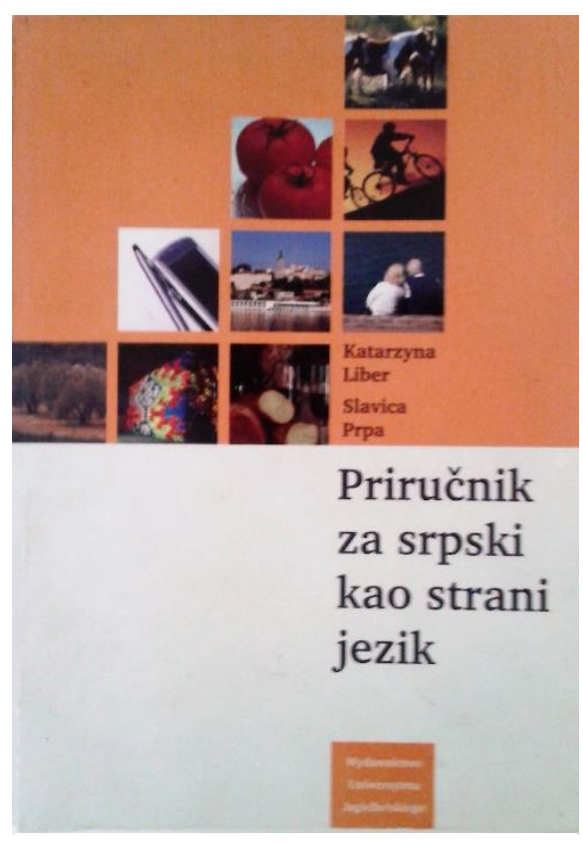

Slika 1: Naslovna strana PZSKSJ vožnje, Zdrav život, Međuljudski odnosi i

Ekologija. Četvrti nivo (str. 97-123) rezervisan je za teme: Privreda, Mediji, Geopolitika, Religija, Festivali, Bolesti XXI veka, Kriminal, Pisanje projekta. Na petom nivou (str. 127-161) susrećemo se sa temama: Identitet, Stereotipi $i$ predrasude, Diskriminacija i tolerancija, Istorija, Nacionalizam i patriotizam, Funkcionalni stilovi, Demokratija i Globalizacija. Poslednji, šesti nivo (str. 165208), sadrži teme: Jezik i komunikacija, Kultura, Književnost i teorija književnosti, Nauka i tehnika, Pravni sistem, Zaštita potrošača, Marketing i Ekonomija. Nakon 
glavnog dela podeljenog po nivoima i temama slede Gramatičke vežbe, na ukupno 23 strane (str. 211-233). U ovom delu vežbe nisu podeljene po nivoima - prepušta se lektoru da odabere sadržaje koji su prikladni za određeni jezički nivo. Podela se odnosi samo na vrste reči koje su srž vežbi, pa su izdvojena četiri odeljka: Imenice, Glagoli, Pridevi i Druge vežbe. Odnos prvog i drugog dela priručnika u skladu je sa ciljem koji su autorke postavile u predgovoru. Poslednju celinu priručnika, od 235. do 272. strane, predstavlja mali rečnik. U predgovoru autorke navode da se radi o srpsko-poljsko-engleskom rečniku jer su, osim rada sa studentima čiji je maternji jezik poljski, kojima je udžbenik prevashodno i namenjen, imale u vidu i kolege koje se bave podučavanjem studenata iz ostalih sredina, te su odrednice napisane i na engleskom jeziku.

U priručniku KŽJ prvi nivo (str. 11-23) sadrži teme: Upoznavanje, Porodica, Osobine čoveka, Profesije $i$ zanimanja, Vreme $i$ vremenska prognoza, $U$ kući, Grad i putovanje i U kupovini i u restoranu. Drugi (od 27. do 43. strane), treći nivo (str. 47-73. strane), četvrti (str. 77-97), peti (str. 101-116) i šesti nivo (str. 117-131) čine oblasti identične onim u PZSKSJ na istim nivoima. I u ovom priručniku poseban dodatak na kraju čini rečnik na 8 strana, od 133. do 140. Osim toga što je vidno manjeg obima od rečnika u PZSKSJ, razliku predstavlja i to što su reči prevedene na poljski, ali ne i na engleski jezik kao što je to slučaj $u$ prethodnom priručniku.

3. Jedna od izuzetno pozitivnih karakteristika priručnika jeste međusobno povezivanje jezičkih veština, kao i povezivanje jezičkih veština sa jezičkim sistemom ${ }^{4}$. Analiza zadataka koji pripadaju različitim jezičkim veštinama obuhvatiće istovremeno oba posmatrana priručnika.

Na prvom nivou vežbe namenjene razvijanju veštine čitanja i razumevanja u potpunosti zadovoljavaju zahteve ZEO (ZEO 2003: 73-76) i student, između ostalog, može da razume kraće i obične poruke sa razglednica, prepozna imena, reči i izraze iz svakodnevnih životnih situacija i nasluti sadržaj nekog običnog informativnog teksta, kao i da prati kraće i jednostavne naznake (npr. kretati se od jednog ka drugom mestu). Ide se čak i preko okvira i pojavljuju se zadaci u kojima se od studenata očekuje da razumeju znakove i plakate na javnim mestima kao što su ulice, restorani i slično, a to su stavke koje su predviđene za nivo A2. Na nivou

\footnotetext{
${ }^{4}$ Pod jezičkim sistemima podrazumevaju se fonološki, leksički (vokabular), gramatički, funkcionalni i diskursni. Jezičke veštine predstavljaju način na koji se upotrebljava jezički sistem. U receptivne veštine ubrajaju se slušanje i čitanje, dok govorenje i pisanje spadaju u produktivne veštine (Scrivener 2005: 27-29).
} 
A2 ispunjeni su gotovo svi zahtevi koji se tiču veštine čitanja, te se student osposobljava da: uoči i izdvoji traženu informaciju iz nekog teksta, prepozna bitne i specifične informacije u većini pisanih dokumenata kao što su pisma, brošure, prospekti, mali oglasi, red vožnje ili kraći novinski članci posvećeni običnim stvarima iz života, da prepozna osnovne tipove standardnih i uobičajenih pisama o poznatim temama (narudžbine, informativna pisma, potvrde itd.), razume kraće lično pismo i dr. Nedostaju vežbe koje bi kod studenata razvile sposobnost razumevanja nekog uputstva o pravilima ponašanja ili praćenja uputstva za upotrebu nekog kućnog aparata. Izostaju i upozorenja na opasnost i znakovi za orijentaciju (verovatno zbog tematskih oblasti koje ne podrazumevaju navedene stavke), ali uključeni su u vežbe za naredni nivo. Na nivou B1 su ispunjeni zahtevi $\mathrm{u}$ tom smislu da se razvijaju kompetencije studenta da: razume opisivanje događaja, osećanja i želja u meri koja mu dozvoljava da održava redovnu prepisku sa prijateljima, da u dužem tekstu pronađe traženu informaciju i objedini potrebne informacije iz istog ili nekog drugog teksta kako bi ispunio neki specifičan zadatak, da pronađe i razume relevantne informacije u uobičajenim pisanim dokumentima $\mathrm{i}$ shvati osnovne zaključke u tekstu pregledno izložene argumentacije, kao i da prepozna plan argumentacije u predstavljanju nekog problema. Pojavljuju se i dodatni zadaci u vidu uputstva za raspoređivanje elemenata na raskrsnici, ali nema tekstova koji bi studentima približili način upotrebe nekog aparata. Na narednom, četvrtom nivou, nakon urađenih vežbi student je u stanju da brzo odredi sadržaj i značaj neke informacije u novinskom članku ili reportaži u širokom opsegu stručnih tema, da razume specijalizovane publikacije izvan svog područja aktivnosti uz povremeno korišćenje rečnika, da razume članke i izveštaje o savremenim problemima društva u kojima autori iznose lični stav ili posebno gledište, kao i složena uputstva sa tematikom iz svoje oblasti, ali izostaju tekstovi koji sadrže detalje koji se odnose na uslove održavanja i primene. Za nivoe C1 i C2 važi isto - zahtevi su ispunjeni i student je u mogućnosti da razume sve vrste korespondencije uz eventualno korišćenje rečnika, da detaljno razume široku skalu tekstova koji se mogu susresti u društvenom životu, na poslu ili školi i prepozna fine nijanse u značenjima određenih stavova i razmišljanja, bilo da su implicitno ili eksplicitno iskazani. Dodatna pažnja posvećena je različitim funkcionalnim stilovima, što je izuzetno značajno. Nedostaju tekstovi u kojima bi se razumela složena uputstva za upotrebu.

Kada je u pitanju veština slušanja, zahtevi (ZEO 2003: 70-73) su na svim nivoima u velikoj meri zadovoljeni, uz nekoliko nedostataka. Na nivou A1 kroz vežbe se student potpuno osposobljava da razume uputstva koja mu se polako i oprezno saopštavaju, kao i da prati obična i kratka obaveštenja. Na nivou A2 
imamo vežbe koje omogućavaju studentu da identifikuje predmet razgovora i shvati osnovni smisao nekog kraćeg oglasa ili poruke, da razume i izdvoji osnovne informacije iz kraćih snimljenih delova. Ono što nedostaje jesu materijali koji bi pomogli da se shvate uputstva za prelaz s jednog mesta na drugo, peške ili javnim prevozom. Na nivou B1 student se kroz zadatke priprema da sledi glavne delove nekog dužeg razgovora, da prati neku konferenciju ili izlaganje iz svog područja aktivnosti, da razume većinu informacija i osnovni smisao informativnih emisija na radiju i drugih snimljenih dokumentarnih programa koji govore o bliskim temama. Nedostaju zvučni zapisi koji razvijaju sposobnost razumevanja detaljno razrađenih stručnih uputstava. Na nivou B2 vežbe razvijaju sposobnost studenta da razume suštinu sadržaja i forme složenih konferencija, govora, izveštavanja i drugih oblika izlaganja iz obrazovne ili stručne sfere, kao i oglase i poruke apstraktne ili konkretne sadržine, da prepozna stanovišta i stavove sagovornika i informativni sadržaj i razume većinu dokumentarnih emisija na standardnom jeziku uz korektno određivanje raspoloženja ili tona govornika. Nakon uspešno urađenih zadataka na nivou $\mathrm{C}$, student može sa lakoćom da prati složene razgovore van sopstvenog delokruga, tokom grupne rasprave i debate, čak iako se radi o apstraktnim, složenim i nepoznatim temama, da shvati do tančina neko obaveštenje, da razume široki opseg snimljenog materijala na nestandardnom jeziku, uz prepoznavanje finih nijansi značenja, implicitnog stava učesnika i odnosa između njih. Ono što nedostaje jesu složena stručna uputstva. Na nivou $\mathrm{C} 2$ student se kroz vežbe slušanja osposobljava da prati neku konferenciju ili stručno izlaganje koje sadrži mnoštvo nekonvencionalnih izraza, regionalizama ili nepoznate terminologije.

Veština pisanja je veoma dobro usklađena sa propisanim zahtevima (ZEO 2003: 64-66; 89-90), pojavljuju se i dodatni zadaci koji nisu predviđeni ovim dokumentom, što pokazuje inventivnost autorki i nameru da se priručnici prilagode savremenim potrebama studenata za napredovanjem. Nakon pređenog nivoa A1, student je bez sumnje u stanju da napiše jednostavne rečenice i izraze o sebi i izmišljenim likovima, o tome gde žive i šta rade, da napiše brojeve i datume, ime, državljanstvo, adresu, datum rođenja, godine života, datum dolaska u zemlju, itd. Zadaci na nivou A2 pomažu studentu da piše povezane rečenice o nekim svakodnevnim aspektima iz njegovog okruženja (o ljudima, mestima, poslu ili školi, uslovima života, obrazovanju, zaposlenju), da napiše kraći opis nekog događaja, dešavanja ili aktivnosti iz ličnog iskustva ili jednostavno lično pismo da bi izrazio zahvalnost ili izvinjenje, kao i da primi i napiše jednostavnu i kratku poruku koja se odnosi na neposredne potrebe. Osim svega predviđenog, uočavamo i vežbe u kojima se traži da studenti izmisle i napišu intervju, oglas, sinopsis za film, formalno pismo, neformalnu čestitku, da istaknu prednosti i mane određene 
pojave ili nastave priču. Na nivou B1 vežbe osposobljavaju studenta da na razložan, jednostavan i neposredan način piše o velikom broju bliskih tema u okviru njegovog područja interesovanja, da opiše osećanja i reakcije, neki stvarni ili izmišljeni događaj i putovanje, ispriča neku priču, da napravi rezime na osnovu objektivne baze podataka o bliskim temama iz svog područja svakodnevnih ili nekih drugih aktivnosti, o tome napiše izveštaj i iznese sopstveno mišljenje, da vodi prepisku donoseći sopstveni sud o nekim apstraktnim sadržajima ili kulturnim događajima kao što su utisci o nekom filmu ili muzičkom programu, da primi poruku u kojoj se traži neka informacija ili objašnjenje za neki problem, da ostavi stilski različite i pregledne beleške za osobe sa kojima je često u kontaktu. Kao dodatak zapažamo zahteve za pisanje eseja u kojima se detaljno upoređuju dve pojave ili da se sastavi anketa. Na nivou B2 student uvežbava da na opsežan način piše o stvarnim ili izmišljenim događajima, poštujući pravila određenih žanrova, da na jasan i razložan način piše o raznovrsnim temama koje se tiču njegovog područja interesovanja, da napiše esej ili izveštaj metodično gradeći argumentaciju, da procenjuje različite ideje ili rešenja u vezi sa nekim pitanjem, da izvrši sintezu informacija i argumenata prikupljenih iz različitih izvora, da piše emotivno intonirana pisma i komentariše stavove osobe sa kojom se dopisuje. Kao dodatni izazov na ovom nivou pojavljuje se popunjavanje obrasca Agencije za privredne registre i pisanje projekta, ali izostaju vežbe u kojima se od studenta zahteva da napiše kritički osvrt na neku knjigu, film ili drugo umetničko delo. Vežbe na poslednja dva nivoa zadovoljavaju predviđene zahteve, tako da je student sposoban da: piše slikovite i maštovite tekstove izgrađenog i sigurnog stila, da priređuje tekst složene sadržine, da opširno argumentuje svoje stanovište i u ličnoj prepisci se izražava jasno i precizno, na vešt i uspešan način, upotrebljavajući jezičke registre u ravni osećanja, asocijativne i šaljive sadržine, da sastavlja priče izuzetno jasnim i tečnim stilom koji je prilagođen određenom književnom rodu ili načinu pisanja, piše složene i problemske izveštaje, članke, eseje ili kritičke osvrte na neko literarno delo, kao i da priredi logičan i efikasan plan teksta koji pomaže čitaocima da uoče važne delove. Na šestom nivou se pojavljuju i dopunski zadaci koji zahtevaju transformaciju iz jednog funkcionalnog stila u drugi i pisanje priče iz različitih uglova posmatranja.

Govorenju je u priručnicima posvećena možda i najveća pažnja jer se od drugog nivoa pa nadalje intenzivno kombinuje sa ostalim veštinama i leksičkim i gramatičkim vežbama. Sa druge strane, postoje određena nepoklapanja sa zahtevima ZEO (ZEO 2003: 59-63, 80-88). Naime, na nivou A2 studentu se kroz zadatke ne upućuje zahtev da uradi već pripremljene, veoma kratke oglase i reklame, da učini i prihvati ponudu, poziv ili izvinjenje, da dobije sve potrebne 
informacije u nekoj putničkoj agenciji, da dobije i isporučuje uobičajena potrošačka dobra i usluge ili koristi sredstva javnog prevoza. Na nivou B1 nema zahteva da se opišu karakteristični detalji nekog događaja, da se prepriča zaplet neke knjige ili filma i opišu sopstvene reakcije, da se ispriča neki san, govori o nadanjima i ambicijama, da osoba obezbedi uslove smeštaja i pregovara sa odgovornima iz neke strane zemlje, da se snalazi u neuobičajenim situacijama $u$ prodavnici, pošti, banci (npr. zahtevati povraćaj neke neispravne robe ili proizvoda), da sastavi žalbu, da se snalazi u većini situacija koje nastupaju prilikom rezervisanja karata u putničkim agencijama ili tokom puta (npr. da pita nekog putnika na kom mestu treba da izađe u malo poznatim krajevima), da objasni kako nešto da se uradi, dajući detaljna uputstva. Na B2 nivou studentu se ne daje mogućnost da vodi pregovore o izlasku iz neke konfliktne situacije, kao što su neprimerena kazna za prestup u saobraćaju, odgovornost za otplatu pričinjene štete u stanu, optužbe povodom nekog udesa, ili da isposluje neko obeštećenje. Ono što imamo u priručniku, a nije eksplicitno propisano u ZEO, odnosi se na opisivanje događaja iz različitih perspektiva (A2) i iznošenje mišljenja iz ugla druge osobe. Generalno, ako posmatramo ovu veštinu, primećuje se da nema zadataka koji podrazumevaju rad u paru ili u grupi, što upućuje na zaključak da je cilj bio prilagođavanje individualnoj nastavi.

U knjizi Applied Linguistics I (Sárosdy 2006: 142-146), kao sinteza svih ranijih razmatranja, navode se tipovi zadataka uz pomoć kojih se stiču i proveravaju receptivne i produktivne jezičke veštine. Budući da su u priručnicima PZSKSJ i KŽJ zastupljeni gotovo svi tipovi predloženih vežbi, stiče se utisak da su autorke imale u vidu navedene smernice.

Prilikom provere receptivnih veština u posmatranim priručnicima javljaju se sledeći tipovi zadataka: 1) dvostruki izbor (tačno/netačno, tačno/netačno/nije navedeno, ispraviti netačnu tvrdnju) - uglavnom iza svake vežbe slušanja u $K \check{Z} J$ pojavljuju se tvrdnje koje treba označiti kao tačne ili netačne, odnosno tačne, netačne ili nisu spomenute. Takođe i u PZSKSJ, na primer, na nivou B1 u lekciji Turizam, nakon čitanja teksta o Beogradu, treba označiti tvrdnje kao tačne ili netačne; 2) višestruki izbor - izabrati jedan od ponuđenih odgovora nakon slušanja priče u lekciji Porodica ili Profesije i zanimanja na nivou A1 u KŽJ; 3) povezivanje (povezivanje pitanja i odgovora - nešto slično imamo kod zahteva da se poveže saobraćajni znak sa značenjem u lekciji Red vožnje na nivou B1 u PZSKSJ; povezivanje sa odgovarajućim pasusom - na nivou $\mathrm{C} 2$ u lekciji Ekonomija treba povezati delove tekstova sa temama na koje se odnose; povezivanje fraze ili rečenice sa praznim mestom u tekstu - na nivou A1 u PZSKSJ u lekciji Porodica potrebno je dopuniti tekst izrazima vezanim za porodični život; 
povezivanje stavova ili izjava sa osobama iz teksta - na B1 u PZSKSJ u lekciji Posao treba povezati CV sa oglasom za posao koji mu najviše odgovara ili na A2 u lekciji Kod lekara povezati izjave sa govornicima; slaganje redosleda pasusa - npr. na šestom nivou u PZSKSJ u okviru teme Nauka i tehnika imamo zadatak u kojem je potrebno pravilno složiti ispreturane pasuse teksta); 4) transfer informacija, odnosno prebacivanje podataka iz čitanog ili slušanog teksta u dijagram, tabelu, mapu, formular i sl. - u PZSKSJ na nivou B1 u lekciji Red vožnje postoji zadatak da se nacrta situacija na raskrsnici na osnovu pročitanih smernica, a u $K \check{Z} J$ na nivou A1 u lekciji Vreme $i$ vremenska prognoza studenti treba da popune tabelu sa vremenom u različitim gradovima Srbije na osnovu onoga što su čuli; 5) popunjavanje praznina (nakon čitanja ili u tekstu koji čitaju - gotovo u svakoj lekciji u PZSKSJ, a takođe i u velikom broju lekcija u $K \check{Z} J$, treba upisati reči koje nedostaju u tekstu, ili ponuđene ili po slobodnom izboru prema smislu; nakon slušanja popuniti praznine preformulisanim izjavama - u KŽJ u lekciji Pravni sistem na $\mathrm{C} 2$ nakon slušanja pitanja i odgovora građana i pravnika potrebno je dopuniti tekst na osnovu izjava ili u toku slušanja); 6) sistemski ostavljene praznine - na svim nivoima, kod obrade određenih leksičkih ili gramatičkih jedinica u tekstu su ostavljene praznine, a zahtev je da se od određene vrste reči napravi neka druga i slično. Na primer, na nivou C1 u PZSKSJ u lekciji Identitet u tekstu koji se čita potrebno je od imenica napraviti prideve; 7) pitanja sa otvorenim završetkom - u KŽJ na petom nivou u lekciji Stereotipi nakon slušanja treba dopuniti rečenice, na nivou B2 u lekciji Geopolitika treba dovršiti izjave nakon slušanja teksta; 8) prevod - povremeno se na svim nivoima, nakon čitanja i komentarisanja nekog teksta, postavlja i zahtev da se tekst prevede sa srpskog (npr. u $K \check{J} J$ na petom nivou u lekciji Identitet treba prevesti Izvod iz Matične knjige rođenih). Ovakav tip zadataka prikladan je samo pod određenim uslovima - ako se radi sa grupama koje su homogene u pogledu maternjeg jezika i ako lektor, u slučaju da je izvorni govornik srpskog jezika, savršeno vlada jezikom svojih studenata ili sa studentima radi osoba čiji maternji jezik nije srpski već jezik studenata.

Ukoliko su u pitanju produktivne veštine i proverava se pisanje, javljaju se tri osnovna tipa zahteva uz podtipove: 1) kontrolisano pisanje (ispravljanje grešaka - u KŽJ na B2 nivou u lekciji Privreda zahteva se od studenata da uoče i isprave nelogičnosti u tekstu, a isto to u PZSKSJ na nivou A2 u lekciji Praznici i tekstu o slavi; preformulisati iskaz - u KŽJ na četvrtom nivou u lekciji Bolesti XXI veka treba zameniti podvučene delove u tekstu tako da smisao ostane isti; višestruki izbor izraza - u PZSKSJ na drugom nivou u lekciji Film i pozorište potrebno je odabrati termine i dopuniti rečenice; popunjavanje praznina kroz 
testiranje gramatike - veoma rasprostranjen tip zadatka u PZSKSJ na svim nivoima, prevod - takođe se pojavljuje kao zahtev na svim nivoima u oba priručnika); 2) usmereno pisanje (popunjavanje formulara - u $K \check{Z} J$ na četvrtom nivou u lekciji Privreda popunjava se formular Agencije za privredne registre; pisanje sažetka teksta - u KŽJ na četvrtom nivou u lekciji Mediji, nakon slušanja intervjua sa direktorom novinske agencije potrebno je napisati što više podataka koje su u snimku čuli; pisanje u odgovarajućem kontekstu ili na zadatu situaciju - u $K \check{J} J$ na trećem nivou u lekciji Posao nakon slušanja teksta o „tajnim kupcima” od studenata se zahteva da zamisle da su oni tajni kupac i napišu izveštaj; odgovor na dat tekst - u PZSKSJ na šestom nivou u lekciji Nauka i tehnika potrebno je napisati komentare na pročitane vesti iz oblasti nauke; transformacija iz neverbalnih izvora - u KŽJ na petom nivou u lekciji Funkcionalni stilovi ponuđena je slika na osnovu koje treba napisati kraće tekstove različitih tipova; slaganje ili neslaganje - u KŽJ na petom nivou u lekciji Marketing potrebno je pismeno obrazložiti stavove o dobrim i lošim reklamama ili na trećem nivou u lekciji Obrazovanje izneti stav o Bolonjskoj deklaraciji, a takođe i u PZSKSJ na šestom nivou u lekciji Kultura izraziti slaganje ili neslaganje sa komercijalizacijom kulture); 3) slobodno pisanje (daje se samo naslov) - u PZSKSJ od trećeg nivoa se pojavljuju slični zahtevi skoro posle svake tematske oblasti.

Kod provere veštine govorenja konstatuje se slična situacija: 1) kontrolisano usmeno izlaganje (odgovor na određen gramatički ili situacioni stimulans - zahtevi da se objasne određeni pojmovi, kao npr. u $K \check{Z} J$ na šestom nivou u lekciji Jezik $i$ komunikacija gde je potrebno objasniti pojmove jezička taksonomija, standardni jezik, akvizicija jezika i kognitivna lingvistika; čitanje naglas - može se primeniti posebno kod kraćih tekstova na nižim nivoima; prepričavanje - u KŽJ na četvrtom nivou u lekciji Kriminal potrebno je nakon slušanja prepričati sadržaj); 2) usmereno usmeno izlaganje (prenošenje poruke odgovori na pitanja nakon slušanih ili pročitanih tekstova u oba priručnika; rezime slušanog ili pisanog teksta - na petom nivou u $K \check{Z} J$ u lekciji Identitet nakon slušanja potrebno je zabeležiti bitne statističke podatke; rešavanje problema $-\mathrm{u}$ $K \check{J} J$ na drugom nivou u lekciji Kod lekara nakon saslušanog snimka potrebno je postaviti dijagnoze pacijentima; diskusija na osnovu slike ili nekog sličnog stimulansa - u PZSKSJ na trećem nivou u lekciji Ekologija slike i njihova značenja predstavljaju podsticaj za diskusiju o ekološki prihvatljivom ponašanju; diskusija u vezi sa zadatom knjigom - u PZSKSJ na šestom nivou u lekciji Književnost $i$ teorija književnosti jedan od zadataka je i diskusija o knjigama i filmovima); 3) slobodno usmeno izlaganje (pripremanje prezentacije na odabranu temu - u KŽJ na trećem nivou u lekciji Obrazovanje potrebno je usmeno predstaviti Istraživačku 
stanicu Petnica; monolog na zadatu temu - u KŽJ na petom nivou u lekciji Istorija jedan od zadataka odnosi se na usmeno izlaganje na temu „Ko kroji našu istoriju”; razgovor o ličnim karakteristikama ili diskusija sa kandidatom o zadatoj temi - u PZSKSJ na šestom nivou u okviru lekcije Kultura postoji diskusija o subkulturi ili kontrakulturi, a isto tako u $K \check{J} J$ na petom nivou u lekciji Identitet potrebno je da student iznese svoje mišljenje o razlici u identitetu Srba, Hrvata, Crnogoraca, Bošnjaka i Bosanaca; opisivanje dobijene slike - u KŽJ na prvom nivou u lekciji Porodica postoji zadatak da se ispriča priča o porodici sa slike).

4. Na samom kraju, ovaj komplet priručnika može se oceniti kao jako dobar nastavni materijal za časove srpskog kao stranog jezika. Priručnici mogu dopunjavati, ali ne i zameniti udžbenike, što se posebno odnosi na niže nivoe na kojima bi najprikladniji bili za sistematizaciju gradiva (na primer, u prvoj lekciji u PZSKSJ kod popunjavanja praznina pojavljuju se skoro svi padežni oblici, a nemoguće je raditi takve zadatke sa apsolutnim početnicima na početku semestra). Jedna od prednosti je i to što su priručnici prilagođeni i individualnoj nastavi. Nema zadataka u kojima se eksplicitno iznosi zahtev da se izvede dijalog ili organizuje debata ili rad u paru, ali lektoru se ostavlja mogućnost prilagođavanja sadržaja većoj grupi. Analizirani priručnici predstavljaju svojevrstan spoj tradicionalne $\mathrm{i}$ savremene nastave jezika. $\mathrm{S}$ jedne strane, vodilo se računa o utvrđenim i proverenim metodičkim i konceptualnim zahtevima koje jedan priručnik ovog tipa treba da ispuni. Sa druge, prilagođeni su aktuelnim potrebama studenata koji su srpski jezik odabrali kao svoje buduće zanimanje i koji su motivisani da nauče što više. Teme koje priručnici sadrže su univerzalne, ali su materijali konstruisani tako da se studentima predstave aktuelni i autentični sadržaji, pre svega kroz pisane tekstove (izvori su srpski internet-portali, dnevne i nedeljne novine, časopisi iz različitih oblasti) i zvučne zapise.

\section{LITERATURA}

Cunningsworth, A. (1995). Choosing your coursebook. Heienemann: Oxford.

Sárosdy, J., Bencze, T. F., Poór, Z., Vadnay, M. (2006). Applied Linguistics I-for BA Students in English. Hungary: Bölcsész Konzorcium.

Scrivener, J. (2005). Learning Teaching - A guidebook for English language teachers - Second Edition. Great Britain: Macmillan Publishers Limited. Pristupljeno 10. 4. 2018. URL: <https://archive.org/stream/LearningTeaching/Learning-Teaching-by-James-Scrivener\#page/n13/mode/2up>.

Sheldon, L. (1988). "Evaluating ELT textbooks and materials". ELT Journal 42(4): 237-246. 
Zajednički evropski okvir za žive jezike: učenje, nastava, ocjenjivanje (2003). Podgorica: Ministarstvo prosvjete.

Jelena R. Perišić

Filozofski fakultet Univerziteta u Novom Sadu - Doktorske studije Jezik i književnost Jagelonski univerzitet u Krakovu Filološki fakultet - Institut za slovensku filologiju Odsek za hrvatsku, srpsku i slovenačku filologiju jelenaperisic91@hotmail.com jelena.perisic@uj.edu.pl

Primljeno: 25. 2. 2019. Prihvaćeno: 29. 5. 2019. 